\title{
Bilingual Peptide Nucleic Acids: Encoding the Languages of Nucleic Acids and Proteins in a Single Self-Assembling Biopolymer
}

Colin S. Swenson ${ }^{1}$, Arventh Velusamy ${ }^{1}$, Hector S. Argueta-Gonzalez ${ }^{1}$, Jennifer M. Heemstra ${ }^{1, *}$

${ }^{1}$ Department of Chemistry, Emory University, Atlanta, Georgia 30322, USA ${ }^{*}$ Correspondence:

jen.heemstra@emory.edu

\section{Abstract/Summary:}

Nucleic acids and proteins are the fundamental biopolymers that support all life on Earth. Nucleic acids store large amounts of information in nucleobase sequences while peptides and proteins utilize diverse amino acid functional groups to adopt complex structures and perform wide-ranging activities. Although Nature has evolved machinery to read the nucleic acid code and translate it into amino acid code, the extant biopolymers are restricted to encoding amino acid or nucleotide sequences separately, limiting their potential applications in medicine and biotechnology. Here we describe the design, synthesis, and stimuli-responsive assembly behavior of a bilingual biopolymer that integrates both amino acid and nucleobase sequences into a single peptide nucleic acid (PNA) scaffold to enable tunable storage and retrieval of tertiary structural behavior and programmable molecular recognition capabilities. Incorporation of a defined sequence of amino acid side-chains along the PNA backbone yields amphiphiles having a "protein code" that directs self-assembly into micellar architectures in aqueous conditions. However, these amphiphiles also carry a "nucleotide code" such that subsequent introduction of a complementary RNA strand induces a sequence-specific disruption of assemblies through hybridization. Together, these properties establish bilingual PNA as a powerful biopolymer that combines two information systems to harness structural responsiveness and sequence recognition. The PNA scaffold and our synthetic system are highly generalizable, enabling fabrication of a wide array of user-defined peptide and nucleotide sequence combinations for diverse future biomedical and nanotechnology applications. 


\section{Introduction:}

Nature encodes information, structure, and function in two basic forms of biopolymers: nucleic acids and proteins. Nucleotide sequences in DNA or RNA encode both genetic information and complementary molecular recognition properties, while amino acid sequences in peptides and proteins convey complex information for structure and function. The robust and adaptable performance of both of these biopolymer structures has been a fundamental driving force for evolution on Earth and explains their continued ubiquitous presence in Nature. Moreover, the straightforward design principles and privileged physicochemical properties of both nucleic acids and proteins position them as attractive materials to leverage and integrate in applications beyond their canonical roles. ${ }^{1-3}$ For example, combining the high density of negative charge of DNA molecules with hydrophobic lipids or organic polymers enables assembly and formation of complex nanostructures including micelles, tubes, and vesicles. ${ }^{4-6}$ While these DNA-polymer conjugates successfully integrate structural responsiveness and can perform sequence-specific recognition, they are difficult to control in biological systems and are limited to anionic backbones. Conversely, peptides are able to express myriad biophysical characteristics through programmable amino acid side-chain functionalities but lack the vast information storage and highly modular molecular recognition capabilities of nucleic acids. The ability to combine the functional properties of nucleic acids and proteins into a single biomolecule would largely overcome these material limitations. A "bilingual" biopolymer, able to simultaneously speak both amino acid and base-pairing languages, would allow for both the information processing capability of nucleobase sequence recognition as well as the structural and functional versatility afforded to peptides and proteins, together creating a powerful tool for biomedical and nanotechnology applications.

Despite these clear advantages, uniting these two chemical functionalities presents a significant logistical challenge. We recognized that peptide nucleic acid (PNA) offered an ideal scaffold for the design of a bilingual biopolymer, as is it capable of storing sequence-specific 
nucleotide code along a neutral pseudopeptide backbone. ${ }^{7-9}$ This backbone imparts a number of desirable properties including extremely high affinity for complementary nucleic acids, enhanced stability in complex biological environments, and most significantly, the ability to incorporate amino acid side-chains at sequence-defined positions. ${ }^{10-12}$ Researchers have used the latter capability to impact properties such as solubility, cell permeability, enhanced base-pairing, and bioconjugation. ${ }^{13-22}$ However, integrating a complex amino acid sequence into the PNA backbone to encode assembly or conformational information has yet to be explored. We hypothesized that strategically placing hydrophobic or hydrophilic amino acid side-chains would enable us to controllably induce self-assembly of amphiphilic structures (Figure 1). We further speculated that addition of a complementary DNA or RNA strand would result in duplex formation with the PNA strand and a dramatic change in amphiphilicity, effectively harnessing the nucleic acid code to direct disruption of the assemblies. Here we demonstrate the design, synthesis, and characterization of such an amphiphilic PNA sequence and show assembly into micellar architectures under aqueous conditions. We also show stimuli-responsive disassembly using miRNA-21, a disease-related RNA target. ${ }^{23}$ Together, these results represent the first example of a bilingual biopolymer capable of simultaneously encoding both amino acid and nucleotide information for utilization in controlled assembly and sequence-specific recognition.
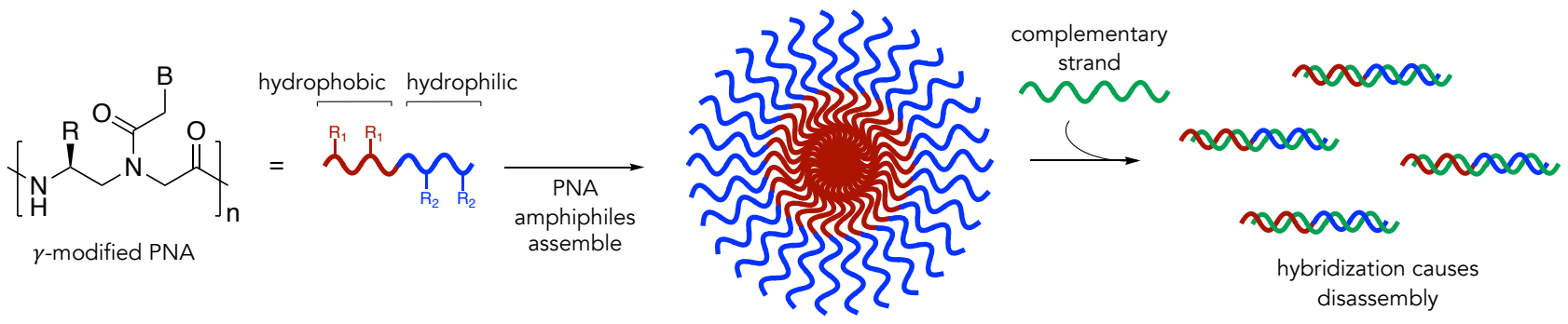

Figure 1: Schematic representation of bilingual PNA biopolymer. Amino acid side-chains at the $\gamma$-position direct assembly, and disassembly is triggered by recognition of the nucleobase code by a complementary DNA or RNA strand. 


\section{Results and Discussion:}

\section{Design and Synthesis of Amphiphilic PNA}

To demonstrate the ability of PNA to function as a bilingual biopolymer, we aimed to create a strand having a nucleobase sequence capable of specific RNA recognition and an amino acid sequence to impart amphiphilic behavior to drive assembly, analogous to folding or quaternary assembly of proteins. As a biologically relevant target, we designed a 12-nucleotide sequence complementary to miRNA-21, a well characterized oncomiR that is upregulated in almost all cancer types. ${ }^{23}$ Conveniently, this complementary sequence exhibits low overall purine content and contains a single guanine nucleobase, averting sequence motifs that are known to be problematic in PNA synthesis and hybridization (Table 1). ${ }^{24}$ To impart hydrophobic properties in our amino acid sequence, we selected an alanine side-chain, as we previously observed aggregation of PNA having three methyl side-chains. For the hydrophilic portion of the sequence, we chose a positively-charged lysine side-chain, which afforded convenient synthetic access and is known to impart favorable solubility properties. ${ }^{12,25}$ The side-chains were placed at the $\gamma$-position along the PNA backbone using L-amino acids, as this enables installation of the side-chains using amino acid precursors, and this location and stereochemistry have been shown to confer increased binding affinity of PNA with complementary DNA and RNA (Figure 1). ${ }^{12,13}$ Lastly, we integrated a solvatochromic fluorophore, 4-dimethylamino-naphthalimide (4-DMN), at the hydrophobic terminus of the PNA (Figure 2). This dye exhibits an enhancement in fluorescence intensity in increasingly hydrophobic environments, ${ }^{26}$ and we envisioned that such an arrangement in the hydrophobic portion would allow us to visualize assembly formation by fluorescence spectroscopy. 
Table 1: Sequences of amphiphilic PNA-A and control PNA-C. "D" (orange) denotes the 4-DMN dye monomer. Subscripts denote the amino acid single letter code. Alanine monomers are in red. Lysine monomers are in blue. Masses were confirmed by ESI-TOF mass spectrometry.

\begin{tabular}{|c|c|c|c|}
\hline Strand & Sequence & Mass $(M+3)^{3+}$ & Found $(\mathrm{M}+3)^{3+}$ \\
\hline PNA-A & $C-D C T_{A} G A C_{A} T A C A_{K} A C T_{K}-N$ & 1254.9174 & 1255.5575 \\
\hline PNA-C & C- Lys ${ }^{+}$D CTGACTACAACT-N & 1240.5718 & 1241.5304 \\
\hline
\end{tabular}

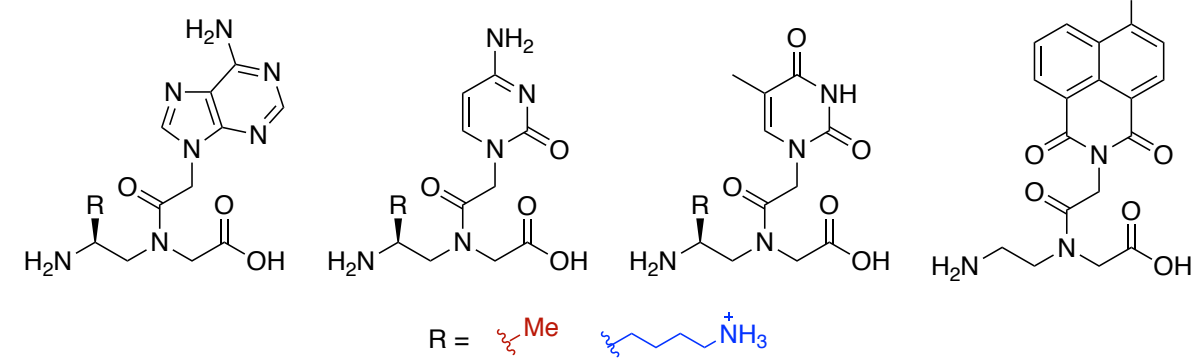

Figure 2: PNA monomers synthesized in this study: $\gamma$-methyl monomers of cytosine and thymine, $\gamma$-lysyl monomers of adenine and thymine, and a solvatochromic 4-DMN monomer.

We first synthesized the necessary $\gamma$-modified PNA monomers according to previously reported procedures. ${ }^{22,25,27-29}$ Starting from Fmoc-protected L-amino acids, PNA backbones containing lysine and alanine side-chains were produced. The $\gamma$-modified backbones were coupled to bis(Boc)-protected nucleobase acetic acids using HATU in the presence of $N-N$ diisopropylethylamine (DIPEA) to produce $\gamma$-modified monomers of A, T, and C (Scheme 1). Synthesis of the 4-DMN PNA monomer was performed using a protocol adapted from that of Saito and coworkers. ${ }^{30}$ First, 4-dimethylamino-naphthalic anhydride was generated by reaction of 4bromo-1,8-naphthalic anhydride with 3-dimethylamino-propionitrile in isoamyl alcohol. ${ }^{31}$ The imide was then produced by condensation with glycine tert-butyl ester hydrochloride in the presence of DIPEA. ${ }^{32}$ Removal of the tert-butyl protecting group by hydrolysis afforded the 4-DMN 
acetic acid. Unmodified (glycine) PNA backbone was synthesized according to previously reported procedure ${ }^{33}$ and the 4 -DMN acetic acid was coupled to the unmodified backbone using HATU/DIPEA conditions to afford the 4-DMN PNA monomer (Scheme 2).

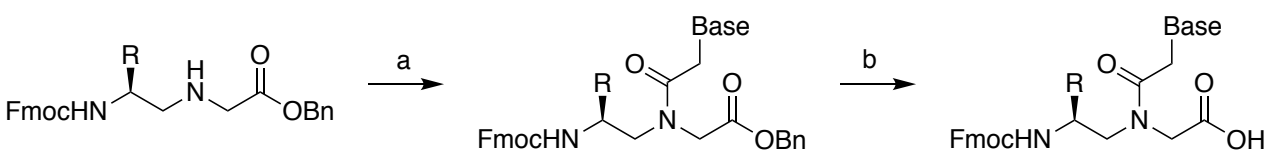
1: R = Lysyl; Base $=$ A
3: $\mathrm{R}=\mathrm{Me} ;$ Base $=\mathrm{C}$
2: $R=$ Lysyl; Base $=\mathrm{T}$
4: $\mathrm{R}=\mathrm{Me} ;$ Base $=\mathrm{T}$

Scheme 1: General coupling procedure for the synthesis of $\gamma$-modified PNA monomers. (a) Nucleobase acetic acid, HATU, DIPEA, DMF; (b) $\mathrm{H}_{2}, \mathrm{Pd} / \mathrm{C}, \mathrm{MeOH}$.

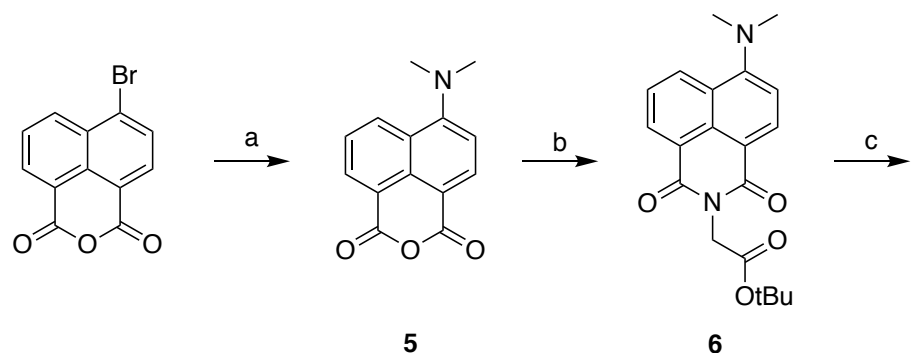

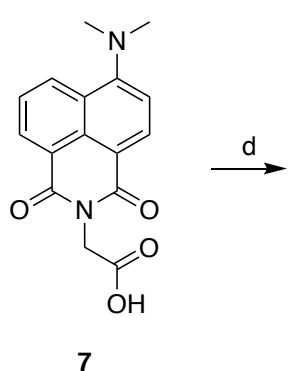

7
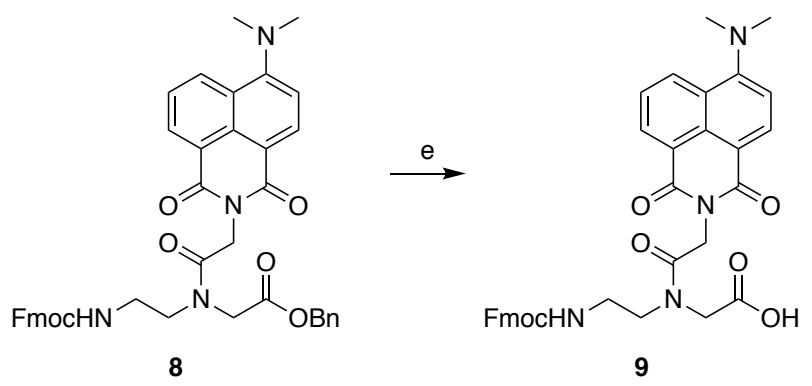

Scheme 2: Synthesis of 4-DMN PNA monomer. (a) 3(dimethylamino)propionitrile, isoamyl alcohol, reflux, quant. (b) Glycine tert-butyl ester hydrochloride, DIPEA, DMF, 78\%. (c) $\mathrm{H}_{2}, \mathrm{Pd} / \mathrm{C}$, methanol, 94\%. (d) Fmoc (aminoethyl)glycine benzyl ester, HATU, DIPEA, DMF, $72 \%$. (e) $\mathrm{H}_{2}, \mathrm{Pd} / \mathrm{C}$, methanol, quant.

Amphiphilic PNA and control PNA oligomers were then produced using solid-phase synthesis employing HATU/DIPEA coupling conditions on a semi-automatic synthesizer with microwave assistance. Initially, we sought to place three hydrophobic side-chains and three 
hydrophilic side chains equally spaced along the backbone. However, we were unable to obtain full-length product with this design. We hypothesized that this was due to the close proximity of semi-consecutive $\gamma$-modified monomers, which could severely lower the efficiency of the coupling reactions, resulting in little to no product formation. With this in mind, we reduced the number of $\gamma$-modified monomers to two alanine and two lysine side-chains. This design allowed placement of at least two unmodified monomers between each $\gamma$-modified residue, thereby mitigating otherwise poor coupling yields due to steric strain. Using this design, we produced an amphiphilic PNA sequence, PNA-A, as well as an unmodified control strand, PNA-C, containing a single Cterminal lysine, as is typically used in PNA strands to ensure solubility (Table 1). The strands were purified by HPLC and characterized by ESI-TOF mass spectrometry to confirm identity (Supplementary Information).

\section{Characterization of Amphiphilic PNA Assembly}

The ability of proteins to form tertiary and quaternary structures based on the information encoded in their primary amino acid sequence is a powerful tool. We envisioned that we could mimic this characteristic of proteins by encoding an amphiphilic amino acid sequence into the PNA backbone. After synthesis and characterization of the PNA strands, we sought to analytically confirm assembly formation and determine the critical micelle concentration (CMC) of PNA-A. To achieve this, we leveraged the ability of the 4-DMN dye to respond to changes in solvation, and we hypothesized that the dye's placement at the hydrophobic portion of the amphiphile should result in enhanced fluorescence upon assembly (Figure $3 \mathbf{A}) \cdot{ }^{26}$ Indeed, we observed a concentration-dependent increase in fluorescence of amphiphile PNA-A over that of the 4-DMN monomer alone, suggesting the formation of assemblies having the dye sequestered in their hydrophobic core. In contrast, the control strand, PNA-C, displayed very little fluorescence enhancement with increasing concentrations, as it does not have an amino acid code to direct assembly (Figure 3B). While PNA-C does show a small amount of fluorescence signal over the 
4-DMN monomer alone, we surmise that this is attributable to the dye's solvation state when placed near a hydrophobic nucleobase in the PNA strand, as opposed to the complete solvation of the free monomer. In any case, directly comparing the monomer-normalized fluorescence ratio of the amphiphile PNA-A with that of the non-assembling control PNA-C, we were able to estimate a CMC of $\sim 353 \mathrm{nM}$, which is sufficiently low for a broad range of stimuli-responsive biological applications.

We next aimed to visually confirm the formation of assemblies and characterize their morphology using transmission electron microscopy (TEM). Amphiphile PNA-A was first dissolved in ultrapure water and diluted to a concentration of $100 \mu \mathrm{M}$. This solution was spotted onto formvar/carbon-coated copper grids and stained using a $1 \%$ uranyl acetate solution for TEM visualization. As expected, we observed the presence of spherical assemblies having an average diameter of $36.9 \pm 9.9 \mathrm{~nm}$, consistent with the formation of micelles (Figure 3C-D). Conversely, the PNA-C control strand displayed only a small number of amorphous assemblies, likely due to uncontrolled aggregation of PNA at this high of concentration or drying effects during sample preparation (Supplementary Figure 1). Together, these results demonstrate our ability to encode amino acid information into a PNA sequence to direct the formation of organized nanostructures under aqueous conditions. 
A

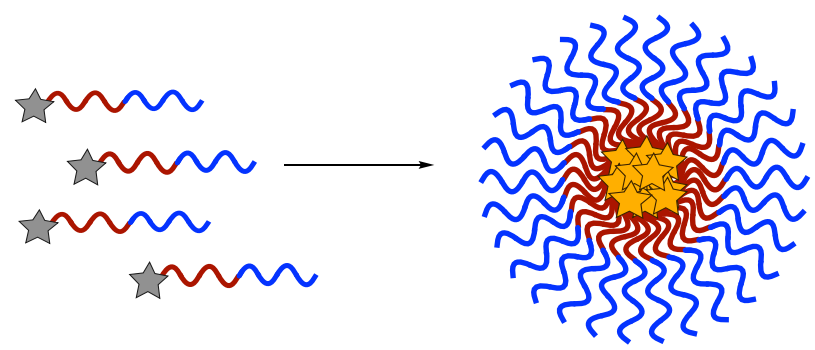

hydrophilic environment (low fluorescence)

hydrophobic environment (high fluorescence)

B

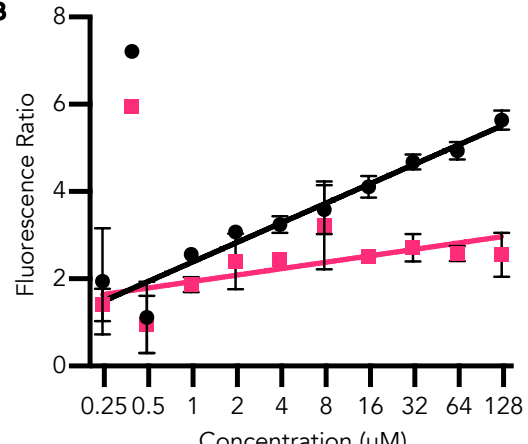

D
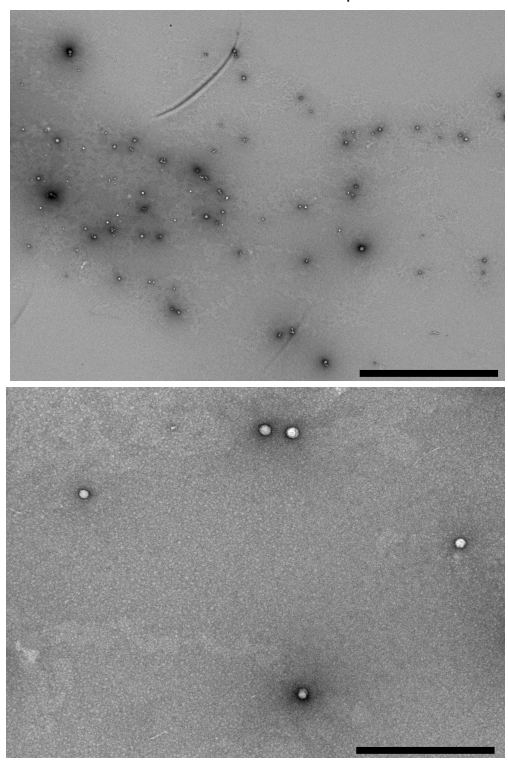

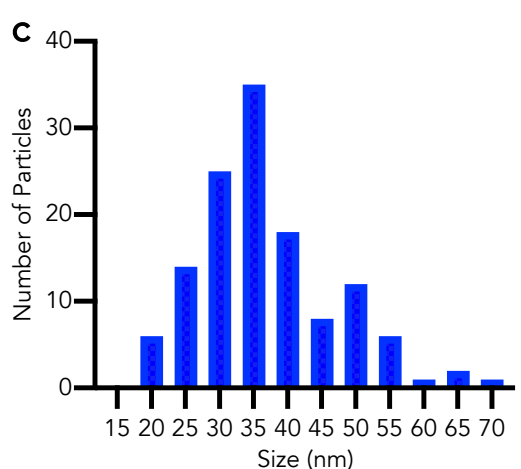
Size $(\mathrm{nm})$
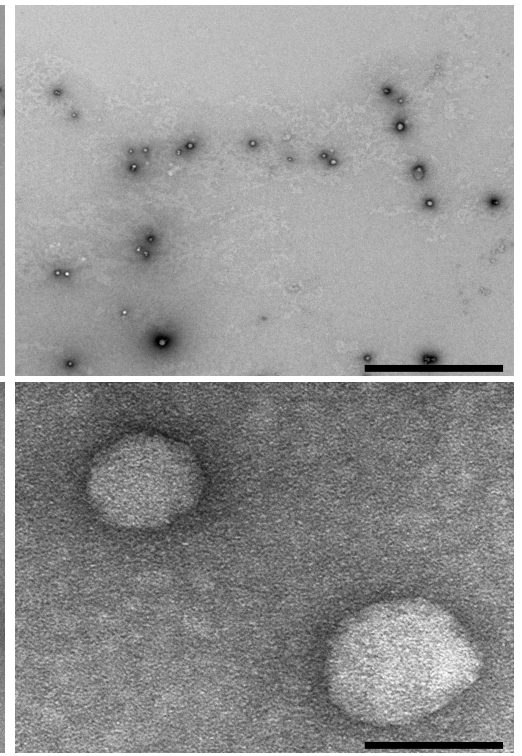

Figure 3: Characterization of amphiphilic PNA assembly. (A) Schematic representation of assembly and subsequent 4-DMN fluorescence response upon encapsulation. (B) Plot of the ratio of PNA-A and PNA-C fluorescence to the 4-DMN monomer as a function of concentration. Error bars represent standard error $(n=3)$. (C) Histogram of the size distribution of particles as measured by ImageJ using TEM images. (D) TEM images of PNA-A at $100 \mu \mathrm{M}$. Scale bars $=2000 \mathrm{~nm}$ (top left), $1000 \mathrm{~nm}$ (top right), $500 \mathrm{~nm}$ (bottom left) and 50 $\mathrm{nm}$ (bottom right). 


\section{Stimuli-Responsive Switching of Amphiphilic PNA Assembly}

Assembly of our PNA amphiphiles is driven by the amino acid code, and we envisioned that disassembly could be driven by the nucleotide code (Figure 4A). While we designed the amphiphilic PNA sequence to be responsive to miRNA-21, we used a complementary 12nucleotide DNA strand in our initial disassembly studies owing to greater ease of use and lower cost. First, we sought to confirm the ability of the complementary DNA to bind to the amphiphilic PNA using circular dichroism (CD). Incorporating $\gamma$-modifications into PNA oligomers imparts chirality and orients the strand into a helical secondary structure, which can be observed by CD spectroscopy at concentrations relevant to assembly formation. ${ }^{14}$ In order to detect PNA:DNA hybridization and subsequent disassembly, we first prepared PNA-A assemblies at $100 \mu \mathrm{M}$ in 1x phosphate buffered saline (PBS), $\mathrm{pH}$ 7.4. A range of concentrations of complementary or scrambled DNA was added to the samples and CD signatures were recorded. We observed signals recording maxima near $263 \mathrm{~nm}$ and $222 \mathrm{~nm}$, with minima occurring near $244 \mathrm{~nm}$ and 201

$\mathrm{nm}$, which are indicative of a right-handed PNA:DNA duplex (Figure 4B). ${ }^{14,34}$ As the concentration of complementary DNA in the samples was increased, the CD signal also increased while maintaining isosbestic points, suggesting a continuous increase in PNA:DNA duplex formation. As expected, we observed no increase in signal when PNA-A was exposed to the scrambled DNA sequence (Figure 4D). In fact, we observed a slight decrease in CD signal for PNA-A in the presence of scrambled DNA, which we speculate could be caused by minor electrostatic interference between the positively charged assemblies and the negatively charged DNA. Having established the ability of PNA-A to decode complementary DNA, we next aimed to explore whether similar decoding could be achieved using miRNA-21. Samples for CD spectroscopy were prepared as previously described at $100 \mu \mathrm{M}$ but using only a single equivalent of RNA. We observed a significant change in CD signal, in particular a large increase in intensity at the 202 
$\mathrm{nm}$ minima, strongly suggesting the ability of miRNA-21 to hybridize with PNA-A in water (Figure 4F).

A

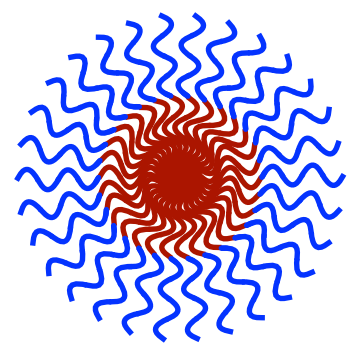

complementary

strand

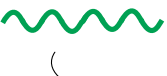

1000000

1000000

1000000

1000000

hybridization causes disassembly

B

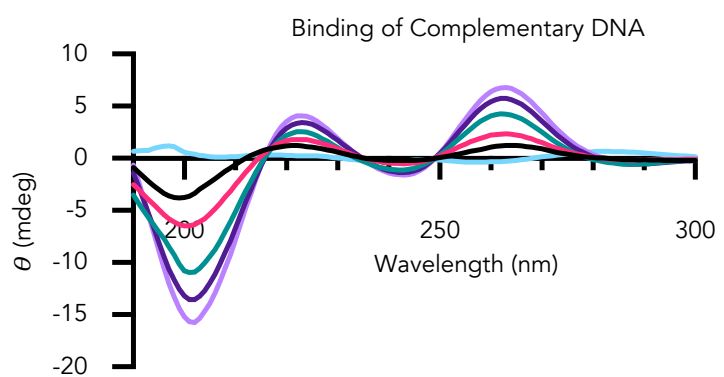

D

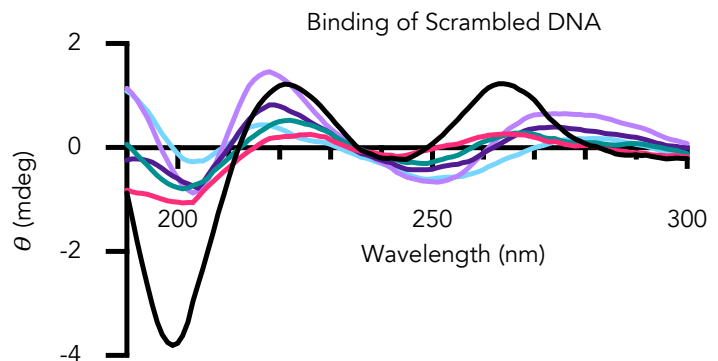

$\mathbf{F}$

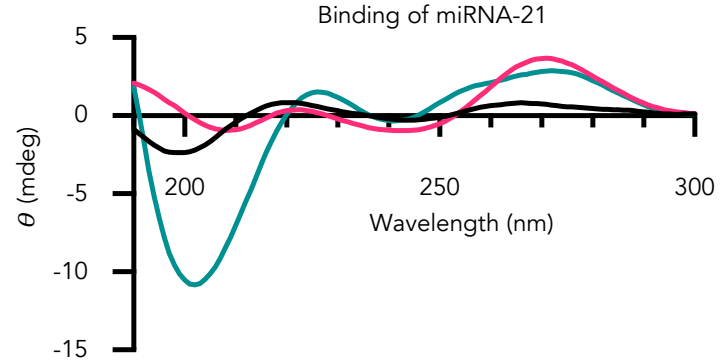

C

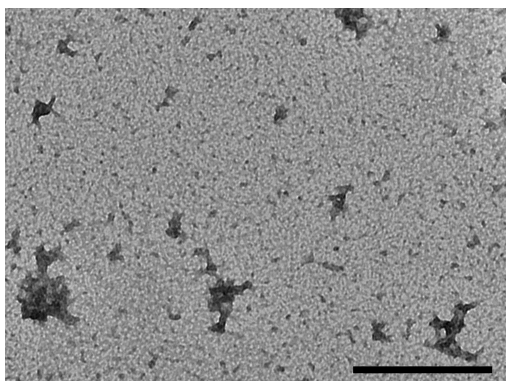

E

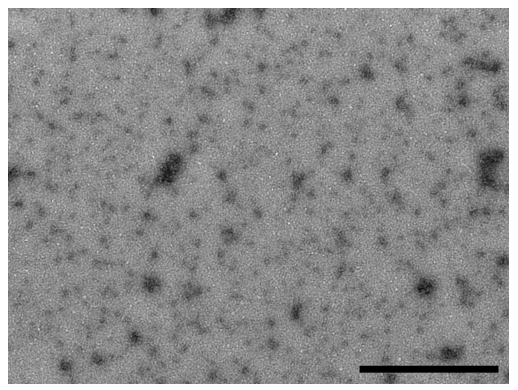

G

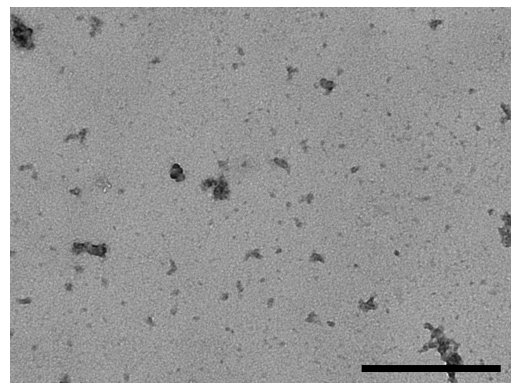

Figure 4: Binding and disassembly of amphiphilic structures by complementary nucleic acids. (A) Schematic representation of disassembly by hybridization of a complementary DNA or RNA strand. (B) CD plot confirming hybridization of complementary DNA to PNA-A in 1x PBS at $100 \mu \mathrm{M}$. (C) TEM image showing disappearance of spherical structures in the presence of complementary DNA. (D) CD plot showing inability of a scrambled DNA sequence to hybridize to PNA-A in 1x PBS at $100 \mu \mathrm{M}$. (E) TEM image showing retention of spherical assemblies in the presence of scrambled DNA. (F) CD plot confirming binding of miRNA-21 to PNA-A in water at $100 \mu \mathrm{M}$. (G) TEM image showing disappearance of spherical structures in the presence of complementary RNA. 
While these results were promising, we wanted to further validate and confirm disassembly using TEM. In order to visualize stimuli-responsiveness to DNA, amphiphile PNA-A assemblies were prepared at a concentration of $200 \mu \mathrm{M}$ in 1x PBS. To these samples was added one equivalent of the complementary or scrambled DNA sequence. The samples were spotted onto grids and stained with uranyl acetate for TEM analysis. As expected, we observed the disappearance of assemblies upon addition of the complementary DNA sequence, indicating stimuli-responsive disruption of the micelles (Figure 4C). As a control, we observed retention of small spherical nanostructures in the presence of non-targeting scrambled DNA, strongly indicating that sequence-specific binding is required for disassembly (Figure 4E). While we also observed some dark aggregates in the presence of both DNA sequences, we speculate this is likely due to the negative stain, uranyl acetate, which non-specifically interacts with phosphate ions present in the DNA backbone and PBS buffer, leading to precipitation. In any case, after confirming binding and stimuli-responsive disassembly by target DNA, we sought to also demonstrate responsiveness to the miRNA target of interest. Based on our previous results showing that one equivalent of DNA was sufficient for binding and disruption of assemblies, we challenged our PNA-A amphiphile constructs with a similar amount of miRNA-21. Assemblies were prepared in water and miRNA-21 was added to give final concentrations of $100 \mu \mathrm{M}$ for both PNA and RNA. The samples were then spotted onto grids and stained with uranyl acetate for TEM visualization. As expected, we observed the disappearance of spherical assemblies in the presence of miRNA-21 (Figure 4G). Consistent with our DNA studies, we observed staining precipitation patterns with miRNA-21, further suggesting that these objects are the result of nonspecific artifactual precipitation between the uranyl acetate stain and phosphate-rich oligomers.

Together, these results demonstrate that both DNA and RNA can bind sequencespecifically to PNA-A and disrupt assembly. Thus, even in the assembled state, the nucleotide 
code of our bilingual PNA constructs can be accessed and used to decode nucleic acid sequence information into supramolecular conformational changes.

\section{Conclusion:}

Nature has evolved two languages for encoding the instructions and functions needed for life. While extant biopolymers are limited to encoding a single language, we introduce here a nonnatural biopolymer that is able to simultaneously encode both. We report the synthesis and characterization of a PNA strand having amino acid-like side-chains comprised of hydrophobic alanine and hydrophilic lysine, which when arrayed in a specific pattern are able to direct assembly in a manner analogous to peptide aggregation or quaternary protein assembly. The PNA strand also carries a specific nucleotide code, which is able to be decoded by complementary DNA or RNA to direct stimuli-responsive disassembly. These assembly and disassembly events can be observed both spectroscopically and using TEM, enabling characterization of the CMC and morphology of the assemblies and the sequence-specific nature of the disassembly process. The PNA scaffold is highly generalizable, allowing for the programming of both nucleotide and amino acid sequences to impart unique biological and physicochemical properties. ${ }^{35}$ Thus, the ability of this information-rich bilingual biopolymer motif to undergo ordered self-assembly and conformationally respond to a variety of nucleic acid targets offers significant potential for applications in nanomedicine and biotechnology. While our initial exploration focused on micellar architectures, we envision that the bilingual biopolymer motif can be harnessed to recapitulate many of the structural motifs found in proteins, such as sheets and coils. Moreover, we anticipate that the ability to simultaneously interpret both of the biological codes can be extended beyond the creation of stimuli-responsive assemblies to also enable the construction of custom adaptors able to mediate precise interactions between specific protein and nucleic acid targets.

\section{Experimental Procedures}


Abbreviations: Fmoc, fluorenylmethyloxycarbonyl; DMF, dimethylformamide; HATU, 1[Bis(dimethylamino)methylene]-1H-1,2,3-triazolo[4,5-b]pyridinium 3-oxid hexafluorophosphate; DIPEA, diisopropylethylamine; TFA, trifluoroacetic acid; DCM, dichloromethane; Boc, tertbutyloxycarbonyl; NMP, N-methyl-2-pyrrolidone.

\section{PNA monomer synthesis}

Unmodified PNA monomers were purchased from PolyOrg, Inc. Fmoc $\gamma$-lysyl and $\gamma$-methyl modified PNA backbones and nucleobase acetic acids of adenosine, thymine, and cytosine were prepared by previously published procedures. ${ }^{22,25,27-29}$ Fmoc-L-amino acids and nucleobase starting materials were purchased from Chem-Impex International, Inc. All other reagents and solvents were purchased from Chem-Impex, Sigma-Aldrich, or Fisher Scientific and used without further purification unless otherwise stated. All dry solvents were distilled and collected from a J. C. Meyer solvent dispensing system prior to use to ensure dryness. Small molecule synthesis was monitored by thin layer chromatography (TLC) on Merck silica gel 60 F254 glass plates and visualized using UV light and staining with a ninhydrin solution followed by heating. Flash chromatography was performed using SiliaFlash F60 grade silica purchased from SiliCycle Inc. Compounds were characterized by proton magnetic resonance $\left({ }^{1} \mathrm{H}\right)$ and carbon nuclear magnetic resonance $\left({ }^{13} \mathrm{C}\right) \mathrm{NMR}$ using a Varian Inova $400 \mathrm{MHz}$ spectrometer containing a Bore Oxford magnet. Spectra were analyzed using the MestReNova software. The mass of compounds was confirmed by the use of an Agilent 6230 electrospray ionization time-of-flight (ESI-TOF) mass spectrometer.

\section{General coupling procedure for PNA monomer synthesis}

Nucleobase acetic acid (1 eq) was dissolved in dry DMF under $\mathrm{N}_{2}$ in a round bottom flask. To the flask was added HATU (1 eq) in dry DMF and DIPEA (2 eq). The mixture was stirred at room temperature for 10 min before addition of $\gamma$-modified PNA backbone (0.67 eq) in dry DMF. 
The mixture was stirred overnight or until consumption of the backbone as confirmed by TLC using ninhydrin staining. Upon completion, the reaction was quenched with $\mathrm{H}_{2} \mathrm{O}$, extracted with ethyl acetate and washed with $1 \mathrm{M}$ hydrochloric acid $(\mathrm{HCl})$, saturated aqueous sodium bicarbonate $\left(\mathrm{NaHCO}_{3}\right), \mathrm{H}_{2} \mathrm{O}$, and brine. The organic layer was dried with anhydrous sodium sulfate $\left(\mathrm{Na}_{2} \mathrm{SO}_{4}\right)$ and concentrated with rotary evaporation. The crude solid was purified by flash column chromatography (hexane to ethyl acetate gradient) to give the protected PNA monomer. The purified benzyl-protected monomer was re-dissolved in methanol under $\mathrm{N}_{2}$. To the solution was added palladium on activated charcoal (7\%/wt.) and the $\mathrm{N}_{2}$ was replaced with a balloon of $\mathrm{H}_{2}$. The reaction was stirred until complete deprotection as confirmed by TLC. Upon completion, the solution was filtered through celite and concentrated with rotary evaporation to produce the final $\gamma$-modified PNA monomer.

Fmoc Lysyl Adenine Monomer (1). (43\% yield) ${ }^{1} \mathrm{H}$ NMR (400 MHz, DMSO-d6, two rotamers) $\delta$ 8.75 (rotamer one, s, 1H) 8.73 (rotamer two, s, 1H) 8.45 (rotamer one, s, 1H) 8.43 (rotamer two, s, 1H) $7.88(\mathrm{~d}, 2 \mathrm{H}) 7.69(\mathrm{t}, 2 \mathrm{H}) 7.26-7.43(\mathrm{~m}, 4 \mathrm{H}) 6.81(\mathrm{~s}, 1 \mathrm{H}) 6.76(\mathrm{~s}, 1 \mathrm{H}) 5.40(\mathrm{~m}, 2 \mathrm{H}) 5.18(\mathrm{~m}$, 2H) 4.18-4.36 (m, 3H) $3.81(\mathrm{~m}, 1 \mathrm{H}) 3.49(\mathrm{~m}, 2 \mathrm{H}) 2.87(\mathrm{~m}, 2 \mathrm{H}) 1.00-1.60(\mathrm{~m}, 6 \mathrm{H}) 1.38(\mathrm{~s}, 9 \mathrm{H}) 1.36$ (s, 18H). ${ }^{13} \mathrm{C}$ NMR (400 MHz, DMSO-d6) $\delta 170.78,170.26,167.04,166.58,156.25,156.03$, $155.64,153.53,150.10,150.02,148.96,144.04,143.91,140.80,140.79,127.80,127.52,127.29$,

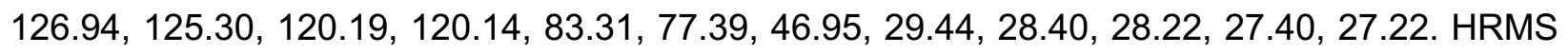
(ESI-TOF) $m / z 887.3907$ (calc'd $\left.[\mathrm{M}+\mathrm{H}]^{+}=887.4298\right)$.

Fmoc Lysyl Thymine Monomer (2). (49\% yield) ${ }^{1} \mathrm{H}$ NMR (400 MHz, DMSO-d6, two rotamers) $\delta$ 11.30 (rotamer one, s, 1H) 11.28 (rotamer two, s, 1H) $7.88(\mathrm{~d}, 2 \mathrm{H}) 7.68(\mathrm{t}, 2 \mathrm{H}) 7.41(\mathrm{t}, 2 \mathrm{H}) 7.32$ $(\mathrm{t}, 2 \mathrm{H}) 7.21(\mathrm{~s}, 1 \mathrm{H}) 6.77(\mathrm{~m}, 1 \mathrm{H}) 4.63(\mathrm{~m}, 2 \mathrm{H}) 4.45(\mathrm{~s}, 1 \mathrm{H}) 4.30(\mathrm{~m}, 2 \mathrm{H}) 4.21(\mathrm{~m}, 2 \mathrm{H}) 3.92(\mathrm{~m}, 2 \mathrm{H})$ $3.35(\mathrm{~m}, 2 \mathrm{H}) 2.88(\mathrm{~m}, 2 \mathrm{H}) 1.72$ (rotamer one, s, 3H) 1.69 (rotamer two, s, 3H) 1.19-1.44 (m, 6H) 
1.36 (s, 9H). ${ }^{13} \mathrm{C}$ NMR (400 MHz, DMSO-d6) $\delta$ 170.32, 167.81, 167.45, 164.43, 156.14, 156.00, 155.62, 151.01, 143.91, 143.83, 140.79, 140.76, 127.66, 127.11, 125.24, 120.17, 108.14, 77.38, 65.34, 47.75, 46.87, 38.29, 29.33, 28.30, 22.90, 22.82, 11.96. HRMS (ESI-TOF) m/z 678.3166 (calc'd $\left.[\mathrm{M}+\mathrm{H}]^{+}=678.3134\right)$.

Fmoc Methyl Cytosine Monomer (3). (43\% yield) ${ }^{1} \mathrm{H}$ NMR (400 MHz, DMSO-d6) $\delta 7.95$ (d, 1H) $7.87(\mathrm{~d}, 2 \mathrm{H}) 7.68(\mathrm{~d}, 2 \mathrm{H}) 7.40(\mathrm{~m}, 3 \mathrm{H}) 7.33(\mathrm{t}, 2 \mathrm{H}) 6.79(\mathrm{t}, 1 \mathrm{H}) 4.84(\mathrm{~m}, 1 \mathrm{H}) 4.67(\mathrm{~m}, 1 \mathrm{H}) 4.26(\mathrm{~m}$, 4H) $3.93(\mathrm{~m}, 2 \mathrm{H}) 3.48(\mathrm{~m}, 2 \mathrm{H}) 1.48(\mathrm{~s}, 18 \mathrm{H}) 1.01(\mathrm{~d}, 3 \mathrm{H}) .{ }^{13} \mathrm{C}$ NMR (400 MHz, DMSO-d6) $\delta$ 168.03, 162.30, 162.22, 155.98, 165.63, 162.11, 149.70, 144.32, 141.14, 128.02, 127.48, 125.65, 120.53, 95.61, 84.92, 64.92, 52.48, 50.41, 48.89, 47.15, 45.68, 27.66, 18.76 HRMS (ESI-TOF) m/z 706.3113 (calc'd $\left.[\mathrm{M}+\mathrm{H}]^{+}=706.3083\right)$.

Fmoc Methyl Thymine Monomer (4). (85\% yield) ${ }^{1} \mathrm{H}$ NMR (400 MHz, DMSO-d6) $\delta 11.25$ (s, broad, 1H) $7.87(\mathrm{~d}, 2 \mathrm{H}) 7.68(\mathrm{~d}, 2 \mathrm{H}) 7.41(\mathrm{~m}, 3 \mathrm{H}) 7.32(\mathrm{t}, 2 \mathrm{H}) 7.22(\mathrm{~s}, 1 \mathrm{H}) 4.63(\mathrm{~m}, 1 \mathrm{H}) 4.44(\mathrm{~m}, 2 \mathrm{H}) 4.25$ (m, 3H) $3.83(\mathrm{~s}, 2 \mathrm{H}) 3.44(\mathrm{~m}, 2 \mathrm{H}) 1.70(\mathrm{~s}, 3 \mathrm{H}) 0.99(\mathrm{~d}, 3 \mathrm{H}){ }^{13} \mathrm{C}$ NMR (400 MHz, DMSO-d6) $\delta$ 168.36, 167.50, 164.86, 155.97, 151.46, 144.40, 144.29, 142.63, 141.13, 128.03, 127.51, 125.68, 120.52, 110.00, 108.37, 65.71, 48.26, 47.17, 45.76, 18.87, 12.32. HRMS (ESI-TOF) m/z 521.2051 (calc'd $\left.[M+H]^{+}=521.2031\right)$.

\section{Synthesis of 4-(dimethylamino)naphthalimide monomer:}

The 4-DMN monomer was synthesized according to an adapted procedure from Saito, et. al. ${ }^{30}$

4-dimethylamino-napthalic anhydride (5). 4-bromo-1,8-naphthalic anhydride (1 eq) dissolved in isoamyl alcohol was brought to reflux in an oil bath. 3-Dimethylamino-proprionitrile (4 eq) was added and the mixture was refluxed overnight. The reaction was cooled to room temperature and 
the precipitate filtered. The precipitate was washed with water and cold hexane and dried under reduced pressure to yield a brown solid in quantitative yield. ${ }^{1} \mathrm{H} N M R\left(400 \mathrm{MHz}, \mathrm{CDCl}_{3}\right) \delta 8.50(\mathrm{~d}$, 1H) $8.46(\mathrm{~d}, 1 \mathrm{H}) 8.37(\mathrm{~d}, 1 \mathrm{H}) 7.65(\mathrm{t}, 1 \mathrm{H}) 7.06(\mathrm{~d}, 1 \mathrm{H}) 3.18(\mathrm{~s}, 6 \mathrm{H}) \cdot{ }^{13} \mathrm{C} \mathrm{NMR}\left(400 \mathrm{MHz}, \mathrm{CDCl}_{3}\right) \delta$ $161.76,160.78,157.98,135.03,133.20,133.00,125.02,124.83,119.19,113.18,109.30,44.69$. HRMS (ESI-TOF) $m / z 242.0834$ (calc'd $[\mathrm{M}+\mathrm{H}]^{+}=242.0812$ ).

4-dimethylamino-naphthalimide tert-butyl acetate (6). To a solution of 4-dimethylamino-napthalic anhydride 5 (36 mmol) and glycine tert-butyl ester $(54 \mathrm{mmol})$ in $180 \mathrm{~mL}$ of dry DMF was added DIPEA (108 mmol). The turbid solution was brought to $80^{\circ} \mathrm{C}$ and stirred overnight or until full consumption of the anhydride by TLC. Upon completion, the reaction was quenched by addition of $250 \mathrm{~mL}$ water and extracted with ethyl acetate $(3 \times 250 \mathrm{~mL})$. The organic layer was washed with water and brine, dried with anhydrous sodium sulfate, and concentrated using rotary evaporation. The crude solid was purified by flash column chromatrography (1:1 ethyl acetate:hexane) to yield a yellow solid (78\%). ${ }^{1} \mathrm{H}$ NMR $\left(400 \mathrm{MHz}, \mathrm{CDCl}_{3}\right) \delta 8.50(\mathrm{~d}, 1 \mathrm{H}) 8.40(\mathrm{~d}, 1 \mathrm{H}) 8.36(\mathrm{~d}, 1 \mathrm{H}) 7.59(\mathrm{t}$, 1H) $7.02(\mathrm{~d}, 1 \mathrm{H}) 4.80(\mathrm{~s}, 2 \mathrm{H}) 3.05(\mathrm{~s}, 6 \mathrm{H}) 1.46(9 \mathrm{H}) .{ }^{13} \mathrm{C}$ NMR $\left(400 \mathrm{MHz}, \mathrm{CDCl}_{3}\right) \delta$ 167.40, 164.28, $163.63,157.20,133.01,132.93,130.45,125.25,125.17,122.58,114.28,113.21,113.11,81.98$ 44.72, 41.96, 28.15. HRMS (ESI-TOF) m/z 355.16595 (calc'd $[\mathrm{M}+\mathrm{H}]^{+}=355.1652$ ).

4-dimethylamino-naphthalimide acetic acid (7). 4-dimethylamino-naphthalimide tert-butyl acetate $6(18 \mathrm{mmol})$ was dissolved in a $50 \%$ mixture of TFA in DCM $(90 \mathrm{~mL})$. After stirring for 3 hours, TLC indicated reaction completion. The reaction was concentrated using rotary evaporation and azeotroped with toluene (3x). The solid was triturated with hexane/DCM, filtered, and the collected solid was dried under reduced pressure to yield the final product as a yellow solid (94\%). ${ }^{1} \mathrm{H}$ NMR (400 MHz, DMSO-d6) $\delta 13.02(\mathrm{~s}$, broad, 1H) $8.40(\mathrm{~d}, 1 \mathrm{H}) 8.35(\mathrm{~d}, 1 \mathrm{H}) 8.21(\mathrm{~d}, 1 \mathrm{H}) 7.66(\mathrm{t}, 1 \mathrm{H})$ $7.08(\mathrm{~d}, 1 \mathrm{H}) 4.67(\mathrm{~s}, 2 \mathrm{H}) 3.04(\mathrm{~s}, 6 \mathrm{H}) .{ }^{13} \mathrm{C}$ NMR (400 MHz, DMSO-d6) $\delta$ 169.59, 163.31, 162.53, 
156.76, 132.53, 131.96, 130.77, 129.66, 124.84, 123.98, 121.67, 112.76, 112.35, 44.34, 40.94 . HRMS (ESI-TOF) $m / z 299.10318$ (calc'd $[M+H]^{+}=299.1026$ ).

Fmoc 4-dimethylamino-naphthalimide (aminoethyl)glycine benzyl ester (8). 4-dimethylaminonaphthalimide acetic acid 7 (2.67 mmol) was dissolved in dry DMF $(15 \mathrm{~mL})$ under $\mathrm{N}_{2}$ in a round bottom flask. The flask was charged with HATU $(2.67 \mathrm{mmol})$ and DIPEA $(4.46 \mathrm{mmol})$. The reaction was stirred for 15 min before addition of Fmoc(aminoethyl)glycine benzyl ester PNA backbone $(1.78 \mathrm{mmol})$ in dry DMF $(5 \mathrm{~mL})$. The reaction was stirred for $2.5 \mathrm{~h}$, at which time TLC showed complete consumption of the backbone. Upon completion, the reaction was quenched with $\mathrm{H}_{2} \mathrm{O}$, extracted with ethyl acetate and washed with $1 \mathrm{M} \mathrm{HCl}$, saturated $\mathrm{NaHCO}_{3}, \mathrm{H}_{2} \mathrm{O}$ and brine. The organic layer was dried with anhydrous sodium sulfate and concentrated by rotary evaporation. The crude yellow solid was purified by flash column chromatography (hexane to ethyl acetate gradient) to provide the product as a yellow solid $(72 \%) .{ }^{1} \mathrm{H} \mathrm{NMR}\left(400 \mathrm{MHz}, \mathrm{CDCl}_{3}\right) \delta 8.51(\mathrm{~d}, 1 \mathrm{H})$ $8.38(\mathrm{~m}, 2 \mathrm{H}) 7.69(\mathrm{~m}, 3 \mathrm{H}) 7.57(\mathrm{~m}, 2 \mathrm{H}) 7.31(\mathrm{~m}, 9 \mathrm{H}) 7.01(\mathrm{~d}, 1 \mathrm{H}) 6.23(\mathrm{t}, 1 \mathrm{H}) 5.15(\mathrm{~s}, 2 \mathrm{H}) 5.10(\mathrm{~s}$ 2H) $4.40(\mathrm{~d}, 1 \mathrm{H}) 4.30(\mathrm{t}, 2 \mathrm{H}) 4.13(\mathrm{~s}, 2 \mathrm{H}) 3.40-3.70(\mathrm{~m}, 4 \mathrm{H}) 3.05(\mathrm{~s}, 6 \mathrm{H}){ }^{13} \mathrm{C}$ NMR $(400 \mathrm{MHz}$, $\left.\mathrm{CDCl}_{3}\right) \delta 169.81,168.08,164.43,163.83,157.23,157.09,144.20,141.29,135.23,133.12$ $131.56,131.46,130.57,128.81,128.68,128.46,128.39,127.64,127.13,125.45,125.20,124.80$, $122.68,119.90,114.41,113.22,67.89,67.34,49.32,49.11,47.29,44.79,40.98,39.66$. HRMS (ESI-TOF) $m / z 711.2901$ (calc'd $[M+H]^{+}=711.2813$ ).

Fmoc 4-dimethylamino-naphthalimide PNA monomer (9). Fmoc 4-dimethylamino-naphthalimide (aminoethyl)glycine benzyl ester 8 (1.49 mmol) was dissolved in methanol $(25 \mathrm{~mL})$ under $\mathrm{N}_{2}$. Palladium on activated charcoal (7\%/wt.) was added to the solution. The $\mathrm{N}_{2}$ was replaced by $\mathrm{H}_{2}$ and the reaction was stirred overnight, after which TLC showed full conversion to product. The reaction was filtered through celite and concentrated using rotary evaporation to provide the 
product as a yellow solid in quantitative yield. ${ }^{1} \mathrm{H}$ NMR $(400 \mathrm{MHz}, \mathrm{DMSO}-\mathrm{d} 6$, two rotamers $) \delta 8.52$ (rotamer one, d, 1H) 8.46 (rotamer two, d, 1H) 8.42 (rotamer one, d, 1H) 8.37 (rotamer two, d, 1H) 8.31 (rotamer one, d, 1H) 8.24 (rotamer two, d, 1H) 7.87 (rotamer one, t, 3H with Fmoc) 7.76 (rotamer two, t, 1H) $7.70(\mathrm{~d}, 2 \mathrm{H}) 7.66(\mathrm{~d}, 2 \mathrm{H}) 7.54(\mathrm{t}, 1 \mathrm{H}) 7.20$ (rotamer one, d, 1H) 7.14 (rotamer two, d, 1H) $4.98(\mathrm{~s}, 2 \mathrm{H}) 4.80(\mathrm{~s}, 2 \mathrm{H}) 4.34(\mathrm{~d}, 2 \mathrm{H}) 4.27(\mathrm{t}, 1 \mathrm{H}) 3.56(\mathrm{t}, 2 \mathrm{H}) 3.15(\mathrm{~m}, 2 \mathrm{H}) 3.10$ (rotamer one, s, 6H) 3.07 (rotamer two, s, 6H). ${ }^{13} \mathrm{C}$ NMR (400 MHz, DMSO-d6) $\delta$ 167.39, 166.82, $136.39,162.67,156.75,156.46,156.13,143.94,140.75,132.41,131.85,130.70,129.75,127.62$ 127.09, 125.20, 124.99, 124.19, 122.05, 120.13, 112.88, 65.64, 46.77, 46.39, 44.39, 44.36, 38.26. HRMS (ESI-TOF) $m / z 621.2399$ (calc'd $[\mathrm{M}+\mathrm{H}]^{+}=621.2344$ ).

\section{PNA oligomer synthesis}

PNA was synthesized on a Biotage SP Wave semi-automatic peptide synthesizer. Synthesis began by down-loading $50 \mathrm{mg}$ of a rink amide MBHA resin $(0.52 \mathrm{mmol} / \mathrm{g})$ with $5 \mu$ mols of the first Fmoc PNA monomer or Fmoc-Lys(Boc)-OH using HATU (1.2 eq), DIPEA (1.2 eq), and 2,6-lutidine (1.2 eq) in $200 \mu \mathrm{L}$ dry NMP for 1 hour at room temperature followed by 1 hour of capping using a solution of $9 \%$ acetic anhydride/13\% 2,6-lutidine in DMF. Successive couplings were performed using microwave assistance at $75^{\circ} \mathrm{C}$ for 6 min with Fmoc PNA monomer (5 eq), HATU (5eq), DIPEA (5 eq) and 2,6-lutidine (5 eq) in $400 \mu \mathrm{L}$ dry NMP. After coupling, capping (2x5 min with $1 \mathrm{~mL}$ capping solution), washing (3x1.1 mL DMF, $3 \times 1.1 \mathrm{~mL}$ DCM, then $3 \times 1.1 \mathrm{~mL}$ DMF), deprotection (3x2 min with $1 \mathrm{~mL} 25 \%$ piperidine/DMF), and washing (same as previous) completed a coupling cycle. All steps were monitored for completion by Kaiser test. Monomer coupling efficiency was monitored by absorbance at $301 \mathrm{~nm}$ of the dibenzofulvene-piperidine adduct using a Nanodrop 2000 spectrophotometer. Upon completion of synthesis, cleavage was performed twice using $500 \mu \mathrm{L}$ of cleavage solution (95\% TFA/2.5\% triisopropylsilane/2.5\% $\mathrm{H}_{2} \mathrm{O}$ ) for $1 \mathrm{~h}$. The crude oligomer was collected by ether precipitation and purified by reverse-phase 
HPLC using an Agilent Eclipse XDB-C18 $5 \mu \mathrm{m}, 9.4 \times 250 \mathrm{~mm}$ column at $60^{\circ} \mathrm{C}$ with a flow rate of $2 \mathrm{~mL} / \mathrm{min}$, monitored at $260 \mathrm{~nm}$ using a linear gradient (10-40\%) of $0.1 \%$ TFA/acetonitrile in $0.1 \%$ TFA/water. Identity was confirmed by ESI-TOF mass spectrometry.

\section{Preparation of PNA amphiphile assemblies}

In order to form uniform assemblies, samples of PNA-A dissolved in water or 1x PBS were heated to $95^{\circ} \mathrm{C}$ for $30 \mathrm{~min}$. The samples were then cooled to room temperature and incubated for at least $1 \mathrm{~h}$ before analysis.

\section{Characterization of assemblies by TEM}

Samples of amphiphile PNA-A and control PNA-C at $100 \mu \mathrm{M}$ were prepared in $\mathrm{H}_{2} \mathrm{O}$ from stock solutions. Assemblies were formed as previously stated. $3.5 \mu \mathrm{L}$ of sample was spotted onto a 200-mesh formvar/carbon-coated copper grid for 2 min before wicking with filter paper. $3.5 \mu \mathrm{L}$ of a $1 \%$ uranyl acetate stain solution was then spotted onto the grids for $30 \mathrm{sec}$ before wicking with filter paper. The grids were allowed to dry at room temperature for 30 min before imaging using a Hitachi HT7700 transmission electron microscope.

\section{Size distribution determination from TEM}

Images were analyzed using the NIH ImageJ software. Particle diameters were measured manually by setting the scale of the image to the scale bar. Lines were drawn and measured in triplicate for each particle that had clear boundaries without overlap in order to accurately determine an average diameter for each particle. A total of 128 particles were measured and a histogram of the data using 12 bins for size was produced using the GraphPad Prism software.

\section{PNA amphiphile CMC determination using internal 4-DMN monomer}


The critical micelle concentration (CMC) of PNA-A was determined by the fluorescent response of the internal 4-DMN monomer. Samples of PNA-A, control PNA-C, and fully deprotected 4-DMN monomer ranging in concentration from $125 \mu \mathrm{M}-0.244 \mu \mathrm{M}$ in $1 \% \mathrm{DMSO} / \mathrm{H}_{2} \mathrm{O}$ were prepared from stock solutions. DMSO was used to initially dissolve the monomer, then stocks were prepared in $\mathrm{H}_{2} \mathrm{O}$ to a final DMSO content of $1 \%$ in each sample. Each sample was treated for amphiphile assembly as previously stated. Samples were then transferred to a 384well clear bottom plate for analysis on a Biotek Cytation5 plate reader. Fluorescence measurements at $550 \mathrm{~nm}$ were collected using an excitation of $440 \mathrm{~nm}$. Absorbance was also measured at $440 \mathrm{~nm}$ to correct for any changes in concentration between PNA samples and the monomer. A plot of the fluorescence enhancement of the PNA samples over the monomer versus concentration was created using GraphPad Prism software and used to estimate the CMC. A semi-logarithmic fit to the data provides equations for PNA-A and PNA-C, which were then compared to determine a CMC value of $353 \pm 106 \mathrm{nM}$.

\section{Confirmation of binding of complementary DNA to PNA-A by CD}

DNA and RNA samples were purchased from Integrated DNA Technologies. Circular dichroism was used to confirm binding and therefore disruption of PNA amphiphile assemblies. Samples of PNA-A were prepared at $200 \mu \mathrm{M}$ in 1x PBS. Assemblies were formed as previously stated. DNA stocks at concentrations of $100 \mu \mathrm{M}, 200 \mu \mathrm{M}, 300 \mu \mathrm{M}$, and $400 \mu \mathrm{M}$ were prepared in 1x PBS. $30 \mu \mathrm{L}$ of PNA-A was mixed with $30 \mu \mathrm{L}$ of DNA stocks to a final concentration of $100 \mu \mathrm{M}$ PNA-A and DNA concentrations of $50 \mu \mathrm{M}, 100 \mu \mathrm{M}, 150 \mu \mathrm{M}$, and $200 \mu \mathrm{M}$ in 1x PBS. Samples were incubated for $1 \mathrm{~h}$ before being analyzed by a JASCO J-1500 circular dichroism spectrometer. Data points were collected every $1 \mathrm{~nm}$ from 190-300 nm using a continuous scanning mode of $200 \mathrm{~nm} / \mathrm{min}$ at $23.5^{\circ} \mathrm{C}$. Samples containing a scrambled DNA sequence were prepared in the same manner and analyzed simultaneously. 


\section{Confirmation of binding of miRNA-21 to PNA-A by CD}

Samples were prepared similarly to analysis by DNA. PNA-A samples of $200 \mu \mathrm{M}$ in water were prepared as previously described. A $200 \mu \mathrm{M}$ stock of miRNA-21 was added to the samples in water to a final concentration of $100 \mu \mathrm{M}$ PNA and $100 \mu \mathrm{M}$ miRNA-21. The samples were incubated for $1 \mathrm{~h}$ before being analyzed.

\section{PNA amphiphile disassembly by complementary DNA on TEM}

Samples of $400 \mu \mathrm{M}$ PNA-A in 1x PBS were prepared from stock solutions. Assemblies were formed as previously stated. To the samples was added complementary DNA or a scrambled DNA sequence in 1x PBS for a final concentration of $200 \mu \mathrm{M}$ PNA-A and $200 \mu \mathrm{M}$ DNA. Samples were incubated at room temperature for $1 \mathrm{~h}$ before preparation for TEM using the same procedure described above.

\section{PNA amphiphile disassembly by complementary RNA on TEM}

Samples of $200 \mu \mathrm{M}$ PNA-A in water were prepared from stock solutions. Assemblies were formed as previously stated. To the samples was added a $200 \mu \mathrm{M}$ stock of miRNA-21 in water to a final concentration of $100 \mu \mathrm{M}$ PNA-A and $100 \mu \mathrm{M}$ miRNA-21. The samples were incubated at room temperature for $1 \mathrm{~h}$ before preparation for TEM.

\section{Supplementary Information}

Supplementary information available: characterization of monomers and PNA sequences, additional TEM images of PNA-A and PNA-C.

\section{Acknowledgements}


This work was supported by the National Science Foundation (DMR 1822262 J.M.H.). The authors also acknowledge the Robert P. Apkarian Integrated Electron Microscopy Core and NMR Research Center at Emory University for access to instruments and technical assistance, and Mr. Steve Knutson for helpful input on the writing of this manuscript.

\section{Author Contributions:}

Conceptualization, C.S.S and J.M.H.; Methodology, C.S.S. and J.M.H.; Investigation, C.S.S., A.V., and H.S.A.; Formal Analysis, C.S.S.; Writing - Original Draft, C.S.S.; Writing - Review \& Editing, C.S.S., A.V., H.S.A, and J.M.H.; Visualization, C.S.S. and J.M.H.; Funding Acquisition, J.M.H.; Supervision, C.S.S. and J.M.H.

\section{Declaration of Interests:}

The authors declare no competing interests.

\section{References:}

1. Seeman, N. C. \& Sleiman, H. F. DNA nanotechnology. Nat. Rev. Mater. 3, 17068 (2018).

2. Sato, K., Hendricks, M. P., Palmer, L. C. \& Stupp, S. I. Peptide supramolecular materials for therapeutics. Chem. Soc. Rev. 47, 7539-7551 (2018).

3. Habibi, N., Kamaly, N., Memic, A. \& Shafiee, H. Self-assembled peptide-based nanostructures: Smart nanomaterials toward targeted drug delivery. Nano Today 11, 4160 (2016).

4. Peterson, A. M. \& Heemstra, J. M. Controlling self-assembly of DNA-polymer conjugates for applications in imaging and drug delivery. Wiley Interdiscip. Rev. Nanomedicine Nanobiotechnology 7, 282-297 (2015).

5. Kwak, M. \& Herrmann, A. Nucleic acid amphiphiles: synthesis and self-assembled nanostructures. Chem. Soc. Rev. 40, 5745 (2011).

6. Zhang, F., Nangreave, J., Liu, Y. \& Yan, H. Structural DNA Nanotechnology: State of the Art and Future Perspective. J. Am. Chem. Soc. 136, 11198-11211 (2014).

7. Egholm, M., Buchardt, O., Nielsen, P. E. \& Berg, R. H. Peptide nucleic acids (PNA). Oligonucleotide analogs with an achiral peptide backbone. J. Am. Chem. Soc. 114, 1895-1897 (1992).

8. Nielsen, P. E. Peptide Nucleic Acid. A Molecule with Two Identities. Acc. Chem. Res. 32, 624-630 (1999).

9. Dueholm, K. L. et al. Peptide nucleic acid (PNA) with a chiral backbone based on alanine. Bioorg. Med. Chem. Lett. 4, 1077-1080 (1994).

10. Egholm, M. et al. PNA hybridizes to complementary oligonucleotides obeying the Watson-Crick hydrogen-bonding rules. Nature 365, 566-568 (1993).

11. Demidov, V. V et al. Stability of peptide nucleic acids in human serum and cellular extracts. Biochem. Pharmacol. 48, 1310-1313 (1994). 
12. Nielsen, P. E., Haaima, G., Lohse, A. \& Buchardt, O. Peptide Nucleic Acids(PNAs) Containing Thymine Monomers Derived from Chiral Amino Acids: Hybridization and Solubility Properties ofD-Lysine PNA. Angew. Chemie Int. Ed. English 35, 1939-1942 (1996).

13. Sforza, S., Tedeschi, T., Corradini, R. \& Marchelli, R. Induction of Helical Handedness and DNA Binding Properties of Peptide Nucleic Acids (PNAs) with Two Stereogenic Centres. European J. Org. Chem. 2007, 5879-5885 (2007).

14. Dragulescu-Andrasi, A. et al. A Simple y-Backbone Modification Preorganizes Peptide Nucleic Acid into a Helical Structure. J. Am. Chem. Soc 128, 10258-10267 (2006).

15. Yeh, J. I. et al. Crystal Structure of Chiral yPNA with Complementary DNA Strand: Insights into the Stability and Specificity of Recognition and Conformational Preorganization. J. Am. Chem. Soc. 132, 10717-10727 (2010).

16. Zhou, P. et al. Novel Binding and Efficient Cellular Uptake of Guanidine-Based Peptide Nucleic Acids (GPNA). J. Am. Chem. Soc 125, 6878-6879 (2003).

17. Sahu, B. et al. Synthesis of Conformationally Preorganized and Cell-Permeable Guanidine-Based y-Peptide Nucleic Acids (үGPNAs). J. Org. Chem. 74, 1509-1516 (2009).

18. Manicardi, A. et al. Cellular Uptakes, Biostabilities and Anti-miR-210 Activities of Chiral Arginine-PNAs in Leukaemic K562 Cells. ChemBioChem 13, 1327-1337 (2012).

19. Dose, C. \& Seitz, O. Single nucleotide specific detection of DNA by native chemical ligation of fluorescence labeled PNA-probes. Bioorg. Med. Chem. 16, 65-77 (2008).

20. Englund, E. A. et al. Programmable multivalent display of receptor ligands using peptide nucleic acid nanoscaffolds. Nat. Commun. 3, 614 (2012).

21. Englund, E. A. \& Appella, D. H. Synthesis of $y$-Substituted Peptide Nucleic Acids: A New Place to Attach Fluorophores without Affecting DNA Binding. Org. Lett. 7, 3465-3467 (2005).

22. De Costa, N. T. S. \& Heemstra, J. M. Evaluating the Effect of lonic Strength on Duplex Stability for PNA Having Negatively or Positively Charged Side Chains. PLoS One 8, e58670 (2013).

23. Kumarswamy, R., Volkmann, I. \& Thum, T. Regulation and function of miRNA-21 in health and disease. RNA Biol. 8, 706-713 (2011).

24. Nielsen, P. E. \& Egholm, M. An Introduction to Peptide Nucleic Acid. Curr. Issues Molec. Biol. 1, 89-104 (1999).

25. Kleiner, R. E., Brudno, Y., Birnbaum, M. E. \& Liu, D. R. DNA-Templated Polymerization of Side-Chain-Functionalized Peptide Nucleic Acid Aldehydes. J. Am. Chem. Soc 130, 4646-4659 (2008).

26. Loving, G. \& Imperiali, B. A Versatile Amino Acid Analogue of the Solvatochromic Fluorophore 4- N,N -Dimethylamino-1,8-naphthalimide: A Powerful Tool for the Study of Dynamic Protein Interactions. J. Am. Chem. Soc. 130, 13630-13638 (2008).

27. Manna, A., Rapireddy, S., Sureshkumar, G. \& Ly, D. H. Synthesis of optically pure yPNA monomers: a comparative study. Tetrahedron 71, 3507-3514 (2015).

28. Porcheddu, A., Giacomelli, G., Piredda, I., Carta, M. \& Nieddu, G. A Practical and Efficient Approach to PNA Monomers Compatible with Fmoc-Mediated Solid-Phase Synthesis Protocols. European J. Org. Chem. 2008, 5786-5797 (2008).

29. Wu, Y. \& Xu, J.-C. Synthesis of chiral peptide nucleic acids using Fmoc chemistry. Tetrahedron 57, 8107-8113 (2001).

30. Ikeda, H., Nakamura, Y. \& Saito, I. Synthesis and characterization of naphthalimidecontaining peptide nucleic acid. Tetrahedron Lett. 43, 5525-5528 (2002).

31. Kollar, J., Hrdlovic, P., Chmela, S., Sarakha, M. \& Guyot, G. Synthesis and transient absorption spectra of derivatives of 1,8-naphthalic anhydrides and naphthalimides containing 2,2,6,6-tetramethylpiperidine; triplet route of deactivation. J. Photochem. 
Photobiol. A Chem. 170, 151-159 (2005).

32. Grimm, J. B. et al. A general method to improve fluorophores for live-cell and singlemolecule microscopy. Nat. Methods 12, 244-250 (2015).

33. Feagin, T. A., Shah, N. I. \& Heemstra, J. M. Convenient and Scalable Synthesis of FmocProtected Peptide Nucleic Acid Backbone. J. Nucleic Acids 2012, 1-5 (2012).

34. Faccini, A. et al. Circular Dichroism Study of DNA Binding by a Potential Anticancer Peptide Nucleic Acid Targeted Against the MYCN Oncogene. 500, 494-500 (2008).

35. Sharma, C. \& Awasthi, S. K. Versatility of peptide nucleic acids (PNAs): role in chemical biology, drug discovery, and origins of life. Chem. Biol. Drug Des. 89, 16-37 (2017). 